Jorge Bullemore C

\title{
RESEÑA:
}

\section{INSIGHTS FOR SALES FORCE SUCCESS: PRACTICAL IDEAS FOR WINNING IN TODAY'S SALES ENVIRONMENT}

\author{
Jorge Bullemore C. \\ Universidad del Desarrollo \\ jbullemore@yahoo.com
} https://doi.org/10.17979/redma.2017.01.018.4861

El libro Insights for Sales Force Success: Practical Ideas for Winning in Today's Sales Environment, o en castellano "visiones para el éxito de las fuerzas de ventas: ideas prácticas para ganar en el entorno de ventas de hoy", es otra pieza maestra de los profesores e investigadores Andris Zoltners, Prabha Sinha y Sally Lorimer. En esta obra los autores abordan la complejidad de la función de ventas en el mundo empresarial moderno. Está escrita a través de treinta y dos capítulos basados en blogs publicados entre el 11 de Julio de 2011 y el 31 de marzo de 2016, y por tanto muy contingentes y actuales.

Las organizaciones modernas enfrentan grandes desafíos por lo que sus fuerzas de ventas requieren de atención y de mejoras constantes. Las temáticas pueden venir de diversas fuentes tales como: cambios en los gustos y necesidades de los consumidores, nuevos competidores, o nuevas regulaciones legales y ambientales. A su vez, los desafíos se pueden presentar por modificaciones y ajustes de la estrategia empresarial de la organización, así como cambios en el 
Jorge Bullemore $\mathrm{C}$

portafolio de productos, o por fusiones y adquisiciones, o también por reestructuraciones organizacionales. A nivel de las áreas comerciales se presentan diversos desafíos como por ejemplo cambios en la estrategia de ventas, en los procesos comerciales, con los colaboradores, en el diseño de la estructura o tamaño, en el desarrollo de planes de entrenamiento y capacitación, sistemas de incentivos, entre otras varias temáticas.

Los autores nos enseñan -tal como en varios otros libros y artículos científicos de su autoría- el Marco del Sistema de la Fuerza de Ventas (Sales Force System Framework) el cual indica que los resultados que obtiene una organización dependerán de una serie de palancas -o drivers-: estrategia de ventas, procesos de ventas y diseño organizacional, colaboradores y actividad de los comerciales. Las firmas pueden usar este marco para identificar los problemas que enfrentan, y mediante una correcta intervención mejorar sus resultados empresariales.

En el capítulo introductorio se presentan diversas temáticas e interrogantes, como por ejemplo, ¿las organizaciones prestan suficiente atención a sus fuerzas de ventas?, o ¿cómo generar un alto desempeño y que sea sostenible en el tiempo?. Para mejorar la fuerza de ventas ¿conviene más una transformación completa o realizar una mejora continua? De manera que sugieren al lector una serie de ideas para lograr mejoras en la productividad comercial, tales como enseñar a los vendedores a usar su tiempo en aquellas tarea y actividades que generarán mayor impacto, o a preparar a las empresas para generar un cambio adaptativo.

En el libro se afirma que no existen las balas de plata, o soluciones únicas y simples para mejorar el desempeño de las áreas comerciales, sino que se trata de gestionar todas las palancas de productividad comercial, y desarrollar las competencias requeridas para un desempeño que sea sostenible en el tiempo. 
Jorge Bullemore $\mathrm{C}$

En el siguiente capítulo se nos habla acerca la estrategia comercial, la cual implica que las organizaciones apunten a los mercados correctos y a aquellos segmentos de mercado que entreguen mejores oportunidades de crecimiento, y donde se pueda entrega un claro valor añadido. Una mejor capacidad de análisis, big data y las nuevas tecnologías apoyan el descubrimiento de nuevas fuentes de crecimiento para las organizaciones. Así entregan varios ejemplos de compañías que aprovecharon el uso de nuevas tecnologías para mejorar sus resultados comerciales.

Una pregunta estratégica que constantemente se hacen los directivos comerciales es ¿quién es el dueño del cliente, la empresa o el comercial? Su respuesta dependerá del lado de la mesa que miremos, sin embargo los autores nos señalan que cuando las organizaciones crean múltiples fuentes de creación de valor los clientes confiarán en varias personas de la empresa, y no en un vendedor. Al contrario, cuando la única fuente de valor añadido es el vendedor, el cliente se sentirá parte solo de dicha relación, y la empresa perderá el control sobre la relación con el cliente.

Otra fuente de mejoramiento comercial para las organizaciones modernas radica en el conocimiento del potencial del mercado donde se vende. Una firma que maneje esta información podrá tomar mejores decisiones en aspectos como la orientación al mercado (targeting), gestión del desempeño, incentivos y compensaciones, entre otras variables de la estrategia comercial.

Otra de las palanca que apoya el logro de mejoras de la función comercial es el manejo de la tensión entre las áreas de ventas y de marketing. Ciertamente ambas área debiesen ser complementarias, en muchas organizaciones no funcionan como tal, sino como silos independientes. Para lograr reales mejoras, los autores sugieren las siguientes estrategias: generación de objetivos comunes 
Jorge Bullemore $\mathrm{C}$

entre ambas dos áreas, la implementación de procesos y sistemas que alienten una correcta y fluida comunicación, y la creación de una cultura que facilite el trabajo en equipo.

En el tercer capítulo del libro los autores desarrollan la temática de procesos de ventas y el diseño organizacional. El éxito requiere que las empresas organicen su proceso comercial en torno al cliente, que maximice la creación de valor añadido y confianza. Así surge la siguiente pregunta ¿organizar a la fuerza de ventas entorno al cliente o al producto? Que no tiene una única ni correcta respuesta, pues dependerá del tipo de mercado en el que se desempeña la empresa, ciclo de vida del producto, entre otras variables.

Otra pregunta que se hacen los autores $-\mathrm{y}$ cientos de directivos comercial a lo largo del mundo- es ¿la empresa tiene la cantidad correcta de vendedores? Esta no tiene una respuesta sencilla, pues el número de vendedores afectará la rentabilidad de las empresas, tanto en la línea de ingresos (o ventas) como en la línea de costes. Es fácil estimar dichos costes, pues se puede usar información histórica, sin embargo es complejo pronosticar ventas. Para tener una decisión lo más certera posible se debe compatibilizar el aspecto financiero con el comercial.

Otro de las palancas que apoya la mejora de las productividades de las organizaciones son los gerentes de ventas -que en algunos de nuestros países son llamados jefes o supervisores comerciales. Este cargo es clave para lograr mejores resultados de los equipos de ventas. Los autores identifican tres importantes roles de los supervisores: como gestores de personas, como gestores de clientes y como gestores del negocio. Es por esto, que las firmas deben entender en qué usan su tiempo los jefes de ventas para así lograr un equilibrio entre los tres roles mencionados anteriormente. 
Jorge Bullemore $\mathrm{C}$

Finalmente, el capítulo se cierra con recomendaciones para el diseño de territorios de ventas, y para esto sugieren el análisis y respuesta de las siguientes preguntas: ¿la fuerza de ventas se está orientando a las cuentas incorrectas?, ¿existen problemas de contratación y retención de vendedores?, ¿hay algo malo en el plan de incentivos?

El libro continua con un capítulo orientado a la gestión del talento en ventas, es decir a la gestión de los recursos humanos. De manera que el éxito dependerá de contratar a los gerentes y vendedores correctos, desarrollar aquellas competencias y habilidades que generan mejores resultados, entre otras funciones.

Los autores sostienen que "en ventas se debe contratar por personalidad, y entrenar competencias". Erróneamente, muchas empresas prefieren comprar talento -es decir atraer vendedores de otras compañías, muchas veces competidores- en vez de desarrollarlo. El mejor proceso de reclutamiento comercial se enfoca en encontrar aquellas competencias y características que hacen la diferencia. Para el desarrollo de aquellas competencias y características que hacen a los mejores vendedores lo primero es mirar a la actual fuerza de ventas, de manera de poder identificarlas, clasificarlas y para luego poder ser desarrolladas.

Otro asunto importante en la gestión del talento en ventas es tener cuidado con las promociones al interior de las empresas. A veces se promueve a un excelente vendedor para el cargo de supervisor, siendo que ambos cargos no ostentan las mismas características ni competencias. De esta manera se puede perder un excelente vendedor para ganar un mal supervisor. Lo clave será seleccionar y desarrollar vendedores que tengan fuertes inclinaciones hacia posiciones de 
Jorge Bullemore $\mathrm{C}$

jefaturas, y entender que el solo hecho de ser un buen vendedor no es un buen predictor en el éxito como gerente de ventas.

El capítulo finaliza haciéndose cargo de la retención de talentos comerciales al interior de las organizaciones. Así los vendedores que renuncian corresponderán a tres segmentos: comerciales de bajo desempeño y con bajo potencial, ejecutivos de ventas con bajo desempeño, pero con un potencial relevante, y ejecutivos comerciales de alto desempeño. En el primer caso, el problema es más bien de un mal reclutamiento y selección, en el segundo se trata de entregar nuevas herramientas para así lograr un mejor desempeño, y en el tercer caso implica trabajar con aquellas estrellas del desempeño dándoles autonomía, aprecio, reconocimiento, incentivos de largo plazo entre otros.

El quinto capítulo se hace cargo de la motivación y direccionamiento de la actividad de vendedores. En general muchas compañías piensan que la mejor -y a veces la única manera- de direccionar comportamientos radica en entregar incentivos monetarios a sus vendedores. Así los autores formulan la siguiente pregunta: ¿su fuerza de ventas es adicta a los incentivos? La mayor parte de los equipos comerciales serán efectivas en un mundo más bien balanceado entre incentivos económicos, mejores herramientas comerciales, una adecuada estructura comercial, buen desarrollo de data y análisis, entre otras. El capítulo continua con un pequeño análisis de los concursos y campañas comerciales. En promedio los vendedores son personas competitivas, les gusta saber cómo lo están haciendo, pero el uso de rankings públicos servirá con aquellos vendedores que estén cerca de los primeros lugares, pues en el caso contrario, podrían desmotivarse generando una reacción y resultados indeseables.

Los autores mencionan que hay cinco maneras en que las metas de ventas más altas conducen a ventas más bajas: directivos muy ambiciosos, sistemáticos 
Jorge Bullemore $\mathrm{C}$

aumentos en las metas de ventas, dinámicas inesperada del mercado, objetivos creados de manera no rigurosa, y la lógica de "desafía a tus estrellas". Cuando solo una $10 \%$ al $20 \%$ de los vendedores no cumple con sus metas, el problema pueden ser ellos mismos, pero cuando la mayor parte de los vendedores no cumplen, el problema son las metas. Otro tema desarrollado por los autores es si los incentivos deben ser función de la veta o de la utilidad, en este sentido dan algunas luces a través de dos preguntas: ¿es la rentabilidad algo estratégico para la empresa?, ¿pueden los vendedores tener control sobre la rentabilidad?, si ambas preguntas tienen una respuesta positiva se proponen cuatro preguntas más: ¿se puede medir el margen por territorio de ventas?, ¿desea compartir la información de márgenes con los vendedores?, ¿los vendedores tienen influencia en los precios?, ¿desea direccionar las ventas hacia productos de mayor margen? Cuando la respuesta de estas preguntas es afirmativa, entonces se recomienda tener sistema de incentivos basados en utilidades.

En el caso de tener una fuerza de ventas global (en varios países), se afirma que no existe un único sistema de incentivos, así los autores mencionan varias características a revisar tales como la madurez de cada mercado, la estructura de canales, cultura de negocios, leyes locales y disponibilidad de la información. A su vez, entregan varias líneas de acción como desarrollo de lineamiento globales, creación de centros de expertos y centralización de la administración.

Concluye el capítulo afirmando que la información de las área comerciales y ventas sirve sólo si pueden ayudar a tomar acciones en los siguientes niveles: vendedores, supervisores y líderes comerciales. Lo clave no son los datos o la tecnología, sino en que los actores de la organización entiendan las dinámicas y procesos que hay detrás. 
Jorge Bullemore C

En el último capítulo, se desarrollan varias ideas acerca de los soportes y apoyos para la fuerza de ventas. Así el éxito comercial dependerá de personas, procesos, data, y herramientas que apoyarán la cadena completa del sistema de ventas. En el mundo moderno se habla bastante de herramientas tecnológicas y sus aplicaciones como el Big Data, sin embargo esto es un medio y no un fin en sí mismo. La convergencia de telefonía móvil, analítica, sistemas contextuales y la nube generarán una gran cantidad de información, transformando ventas, y permitiendo que compradores y vendedores se comprometan de formas más eficientes y efectivas. Algunas de las tecnologías que tienen ( $y$ tendrán) mayor impacto en las fuerzas de ventas son: computación en todas partes, analítica, sistemas ricos en contexto y tecnología cloud. Lo anterior, sumando a nuevas tecnologías que seguirán apareciendo obliga a que las organizaciones, y por supuesto los vendedores se adapten y adopten están nuevas tecnologías para así mejorar su procesos de ventas y servir mejor a sus clientes.

Esta obra sintetiza de excelente forma las problemáticas comerciales a las que se enfrentan las organizaciones modernas, y entrega de manera clara y precisa varias herramientas para que directivos, vendedores y consultores puedan mejorar las productividad en ventas.

Zoltners, A. Sinha, P. Lorimer, S. (2016). Insights for Sales Force Success: Practical Ideas for Winning in Today's Sales Environment. ZS Associates, Inc. 